\title{
Contribution of organic carbon to wood smoke particulate matter absorption of solar radiation
}

\author{
T. W. Kirchstetter ${ }^{1,2}$ and T. L. Thatcher ${ }^{3}$ \\ ${ }^{1}$ Environmental Energy Technologies Division, Lawrence Berkeley National Laboratory, Berkeley, USA \\ ${ }^{2}$ Civil and Environmental Engineering Department, University of California, Berkeley, USA \\ ${ }^{3}$ Civil and Environmental Engineering Department, Cal Poly, San Luis Obispo, USA
}

Correspondence to: T. W. Kirchstetter (twkirchstetter@lbl.gov)

Received: 28 January 2012 - Published in Atmos. Chem. Phys. Discuss.: 23 February 2012

Revised: 24 May 2012 - Accepted: 22 June 2012 - Published: 16 July 2012

\begin{abstract}
A spectroscopic analysis of 115 wintertime particulate matter samples collected in rural California shows that wood smoke absorbs solar radiation with a strong spectral selectivity. This is consistent with prior work that has demonstrated that organic carbon (OC), in addition to black carbon (BC), appreciably absorbs solar radiation in the visible and ultraviolet spectral regions. We apportion light absorption to $\mathrm{OC}$ and $\mathrm{BC}$ and find that the absorption Ångström exponent of the light-absorbing $\mathrm{OC}$ in these samples ranges from 3.0 to 7.4 and averages 5.0. Further, we calculate that OC would account for $14 \%$ and BC would account for $86 \%$ of solar radiation absorbed by the wood smoke in the atmosphere (integrated over the solar spectrum from 300 to $2500 \mathrm{~nm}$ ). OC would contribute $49 \%$ of the wood smoke particulate matter absorption of ultraviolet solar radiation at wavelengths below $400 \mathrm{~nm}$ and, therefore, may affect tropospheric photochemistry. These results illustrate that $\mathrm{BC}$ is the dominant light-absorbing particulate matter species in atmospheres burdened with residential wood smoke and OC absorption is secondary but not insignificant. Further, these results add to the growing body of evidence that lightabsorbing OC is ubiquitous in atmospheres influenced by biomass burning and may be important to include when considering particulate matter effects on climate.
\end{abstract}

\section{Introduction}

This article is about the relative contributions of black and organic carbon (BC and $\mathrm{OC}$ ) to the absorption of solar radiation by wood smoke particulate matter. BC, combustion- generated particulate matter that appears black in sunlight, is the primary light-absorbing component of atmospheric particulate matter (IPCC, 2007). The spectral absorption of BC is reasonably well approximated by a power law relationship from the near ultraviolet to the near infrared:

$\operatorname{absorption}(\lambda) \propto \lambda^{-\mathrm{AAE}}$

where the symbol $\propto$ means "is proportional to", $\lambda$ is wavelength, and the exponent is referred to as the absorption Ångström exponent (AAE). The interested reader can refer to Moosmüller et al. (2011) for a theoretical discussion of AAE. With an AAE of approximately 1, freshly emitted BC absorbs solar radiation without much wavelength selectivity (Kirchstetter et al., 2004). The observation that particulate matter, and especially biomass combustion-generated particulate matter, can exhibit AAEs much greater than 1 is the basis for concluding that species other than $\mathrm{BC}$ contribute to absorption of solar radiation, namely biomass smoke OC (Hoffer et al., 2006; Kirchstetter et al., 2004). Here, we consider that $\mathrm{OC}$ is the collection of hundreds or more particlephase organic compounds, some of which absorb solar radiation. Biomass smoke particles often look brown rather than black because, compared to $\mathrm{BC}$, they absorb solar radiation with stronger wavelength selectivity in the blue and ultraviolet spectral regions, which has led to use of the term brown carbon to refer to biomass smoke particulate matter (Andreae and Gelenscer, 2006). AAE values for biomass smoke (or brown carbon) generally range from greater than 1 to about 3 (Kirchstetter et al., 2004; Bergstrom et al., 2007; Sandradewi et al., 2008; Rizzo et al., 2011). The range reflects variation in combustion conditions and the chemical composition of the

Published by Copernicus Publications on behalf of the European Geosciences Union. 
observed particles. A few studies have estimated the mass specific absorption of wood smoke OC (in units of $\mathrm{m}^{2} \mathrm{~g}^{-1}$ ), which tends to be at least an order of magnitude smaller than that of BC at visible wavelengths (Sun et al., 2007; Kirchstetter et al., 2004; Barnard et al., 2008). The fact that OC is often much more abundant than BC in wood smoke (Piazzlunga et al., 2011) suggests that the contribution of OC to wood smoke absorption of solar radiation can, however, be significant.

\section{Methods}

We consider the spectral absorption selectivity of 115 particulate matter samples that were collected outside of 12 houses in the residential community of Cambria, which is located in a rural portion of San Luis Obispo County, California. In Cambria, wood burning is prevalent and the only significant source of nighttime particulate matter generation (Thatcher et al., 2011). It is likely that many residents burn Pinus radi$a t a$, also known as Monterey Pine, as it is the native species in region. Particulate matter samples were collected during evening and nighttime hours (from 18:00 h to 06:00 PST) in the winter (of 2010) to maximize the collection of wood smoke particles and minimize the collection of particles from other anthropogenic or natural sources, such as restaurants along the single main street in downtown Cambria. Elevated chimney temperatures, measured using an infrared camera, verified that residents were operating their fireplaces. Little vehicle activity was observed in the area during the evening and nighttime. Particulate matter samples were collected on quartz filters using a sampling device equipped with a single stage impactor to select particles smaller than $2.5 \mu \mathrm{m}$ in aerodynamic diameter (SKC Inc. PEM model 200).

Samples were analyzed using a spectrometer in transmission mode in a manner similar to that described by Kirchstetter et al. (2004). Light transmission through (dry) particulate matter on quartz filters is predominantly due to particle light absorption rather than particle light scattering when the particulate matter is even weakly absorbing (Arnott et al., 2005):

$\operatorname{absorption}(\lambda)=k^{\prime} \operatorname{ATN}(\lambda)$

where $k^{\prime}$ is nominally constant and $\operatorname{ATN}(\lambda)$ is the optical attenuation computed from measured transmission, $T(\lambda)$ :

$\operatorname{ATN}(\lambda)=-100 \ln [T(\lambda)]$

Further, Bond (2001) reported that particle light scattering does not significantly affect spectral absorption selectivity. Thus, we compute the AAE for each particulate matter sample by performing a linear regression of $\ln (\mathrm{ATN})$ against $\ln (\lambda)$ over the visible and near ultraviolet spectral range $360<\lambda<700 \mathrm{~nm}$.

We estimate the contribution of BC to each sample's spectral attenuation, $\operatorname{ATN}_{\mathrm{BC}}(\lambda)$, by (a) attributing all attenuation at $880 \mathrm{~nm}$ to $\mathrm{BC}$, an assumption consistent with prior work (Kirchstetter et al., 2004; Sun et al., 2007), and (b) extrapolating to other wavelengths assuming that the $\mathrm{AAE}$ of $\mathrm{BC}$ is 0.86 . This is the minimum AAE value exhibited by the wood smoke particulate matter samples in this study and it is close to the nominal value of 1 that theory predicts for small BC particles (Bohren and Huffman, 1998). The contribution of OC to each sample's spectral attenuation, $\operatorname{ATN}_{O C}(\lambda)$, is determined by subtracting the $\mathrm{BC}$ attenuation from the total attenuation:

$\operatorname{ATN}_{\mathrm{OC}}(\lambda)=\operatorname{ATN}(\lambda)-\operatorname{ATN}_{\mathrm{BC}}(\lambda)$

Based on the apportionment of spectral attenuation to $\mathrm{BC}$ and OC, we compute for every wood smoke sample the fraction of radiation at each wavelength in the solar spectrum that would be absorbed by OC:

$f_{\mathrm{OC}}(\lambda)=\operatorname{ATN}_{\mathrm{OC}}(\lambda) / \operatorname{ATN}(\lambda)$

Last, we compute the fraction of solar radiation that $\mathrm{OC}$ in the wood smoke would absorb in the atmosphere:

$$
F_{\mathrm{OC}}=\frac{\int_{300 \mathrm{~nm}}^{2500 \mathrm{~nm}} f_{\mathrm{OC}}(\lambda) i(\lambda) d \lambda}{\int_{300 \mathrm{~nm}}^{2500 \mathrm{~nm}} i(\lambda) d \lambda}
$$

where $i(\lambda)$ is the clear sky air mass one global horizontal solar spectrum at the earth's surface (Levinson et al., 2010).

Gyawali et al. (2009) noted that coatings of non-absorbing species may collapse the fractal aggregate structure of BC particles and, consequently, increase spectral absorption selectivity. Therefore, it is conceivable that in applying Eq. (4), we may attribute a portion of the optical attenuation of particulate matter samples to light-absorbing $\mathrm{OC}$ rather than nonabsorbing OC that increases BC absorption selectivity.

Other measurement artifacts warrant mention. A filterloading artifact that causes $k^{\prime}$ (Eq. 2) to increase as the collection filter becomes increasingly loaded with particles may be important for determining spectral absorption selectivity. Studies acknowledging the filter-loading artifact provide mixed evidence - on one hand indicating that the filter-based light transmission method accurately measures the spectral dependence of particulate matter light absorption (e.g., Weingartner et al., 2003) and, on the other hand, indicating that this artifact is wavelength dependent (e.g., Schmid et al., 2006). Generally speaking, this artifact is most pronounced for highly absorbing particulate matter, such as black soot from diesel engines or kerosene flames (Kirchstetter, 2007; Arnott et al., 2005), which the particulate matter in this study is not. In the present study, there is no correlation between filter loading expressed in terms of ATN at $880 \mathrm{~nm}$, which ranged between 3 and 23 for $98 \%$ of samples, and AAE (linear correlation coefficient, $R^{2}=0.003$ ). Thus, we do not expect this artifact to have a large influence on our results. 
Table 1. Derived values of OC AAE and OC contribution to wood smoke absorption of solar radiation as they depend on the chosen value of BC AAE.

\begin{tabular}{lllllll}
\hline & & \multicolumn{5}{c}{$\begin{array}{c}\text { Fraction of solar radiation absorbed by OC rather than BC in } \\
\text { wood smoke at the wavelength or spectral region indicated }\end{array}$} \\
\hline BC AAE & OC AAE & $400 \mathrm{~nm}$ & $500 \mathrm{~nm}$ & $600 \mathrm{~nm}$ & full solar spectrum & UV $^{2}$ \\
\hline 0.86 & 5.00 & 0.43 & 0.26 & 0.11 & 0.14 & 0.49 \\
1.00 & 5.48 & 0.36 & 0.20 & 0.06 & 0.10 & 0.42 \\
1.15 & 6.19 & 0.28 & 0.13 & 0.00 & 0.07 & 0.34 \\
\hline
\end{tabular}

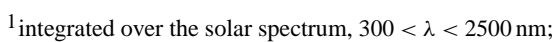

${ }^{2}$ integrated over the ultraviolet region of the solar spectrum, $300<\lambda<400 \mathrm{~nm}$.

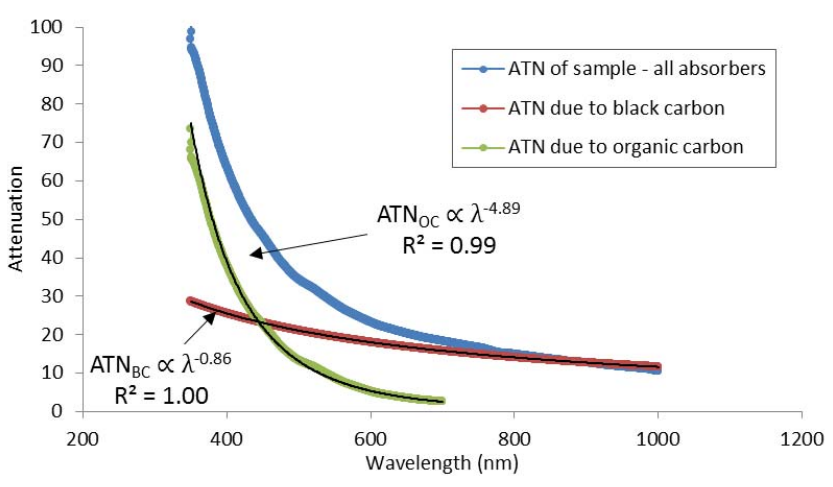

Fig. 1. Estimated contributions of black and organic carbon to the spectral attenuation of a residential wood smoke particulate matter sample. The exponents of the power law trend lines, 0.86 and 4.89, are the absorption Angström exponents of the black and organic carbon, respectively, for this sample.

\section{Results}

Figure 1 shows the spectral attenuation of a particulate matter sample, which is similar to the spectral attenuation of many other samples in this study. The AAE value for this sample is 2.36. As noted above, we estimate the contribution of $\mathrm{BC}$ to this sample's spectral attenuation, $\operatorname{ATN}_{\mathrm{BC}}(\lambda)$. As shown, BC accounts for the overwhelming majority of this sample's attenuation at wavelengths above $700 \mathrm{~nm}$. At shorter wavelengths, the sample absorbs more radiation than is attributed to BC. The difference is attributed to attenuation by $\mathrm{OC}, \operatorname{ATN}_{\mathrm{OC}}(\lambda)$, as illustrated in Fig. 1. OC attenuation rises sharply with decreasing wavelength and is well described by a power law over the wavelength region shown. The AAE of OC is 4.89 for this sample.

We perform this analysis for all samples and generate the AAE histograms shown in Fig. 2. The AAE of all wood smoke particulate matter samples ranged from 0.86 to 3.48 and averaged $1.89(n=115)$. These AAE values are consistent with the predominance of wood smoke during sample collection. The AAE of OC in the wood smoke samples ranged from 3.02 to 7.39 and averaged $5.00(n=87$, AAE values cannot be computed for a minority of samples because

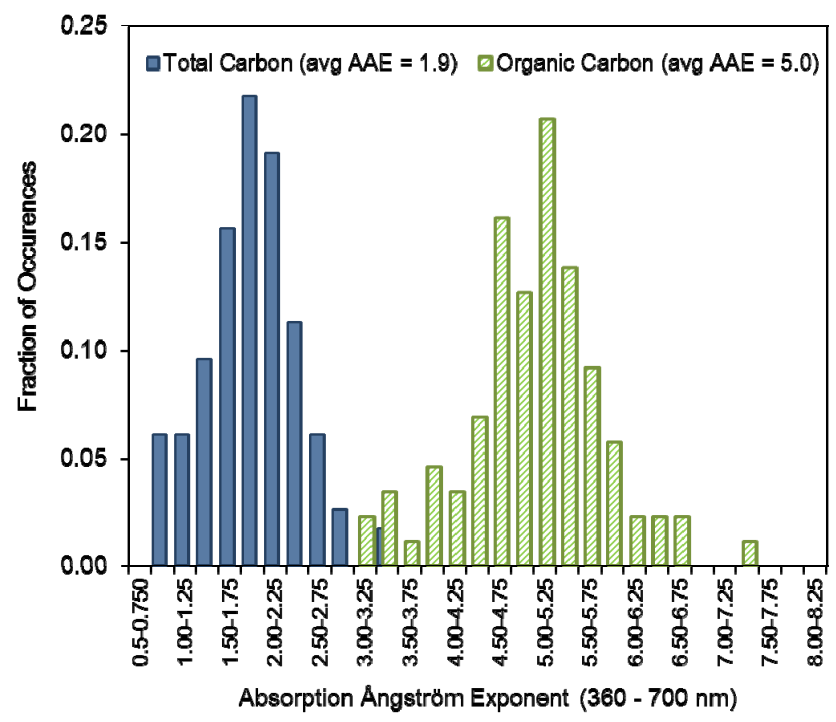

Fig. 2. Histograms of absorption Ångström exponents computed over the 360 to $700 \mathrm{~nm}$ spectral range: (blue bars) 115 residential wood smoke samples considered in this study and (green bars) the light-absorbing organic carbon portion in 87 of the wood smoke samples.

application of Eq. (4) yields some slightly negative values of OC attenuation). These AAE values for OC are consistent with those recommended by Sun et al. (2007), who used band-gap and Urbach relationships to describe the absorption spectra of water-soluble humic-like $\mathrm{OC}(\mathrm{AAE}=6)$ and more polymerized $\mathrm{OC}(\mathrm{AAE}=4)$.

Based on the apportionment of spectral attenuation to BC and OC (as illustrated in Fig. 1), we compute (Eq. 5) for every wood smoke sample the fraction of spectral radiation that would be absorbed by $\mathrm{OC}$ rather than $\mathrm{BC}, f_{\mathrm{OC}}(\lambda)$. The averages and standard deviations are shown in Fig. 3. The red line in Fig. 3 is a model of $f_{\mathrm{OC}}(\lambda)$ based on a 5th order polynomial fit of our measurements (our spectrometer operated between 350 and $990 \mathrm{~nm}$ ), a prescribed value of zero above $880 \mathrm{~nm}$ (rather than unrealistic negative values), and a linear extrapolation of the data below $350 \mathrm{~nm}$. The fraction of light absorbed by the wood smoke particulate matter that we 


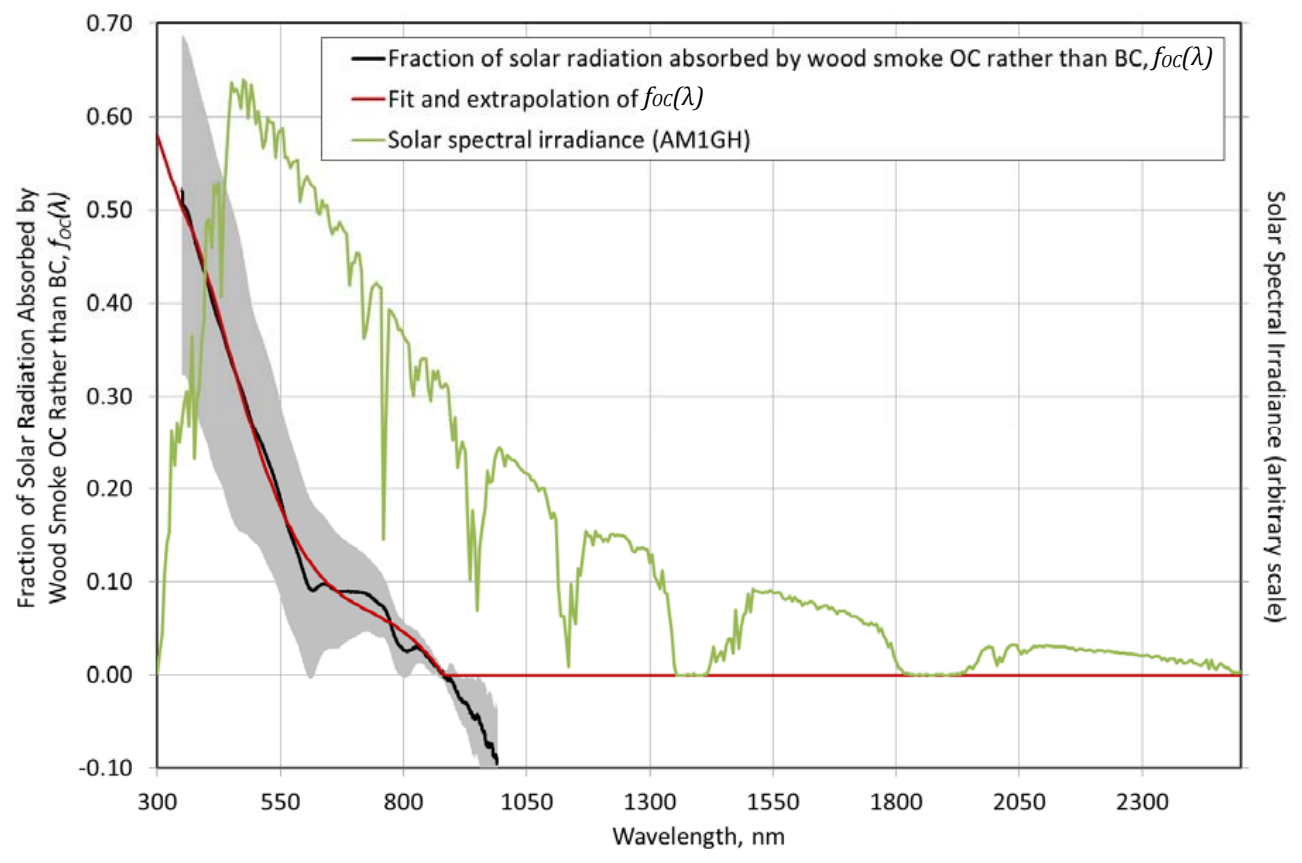

Fig. 3. Fraction of solar radiation absorbed by organic carbon rather than black carbon in residential wood smoke particulate matter, $f_{\mathrm{OC}}(\lambda)$ : (black line and gray region) average values for 115 samples \pm 1 standard deviation and (red line) a model fit and extrapolation of the data. Also shown (green line) is the clear sky air mass one global horizontal (AM1GH) solar spectrum at the earth's surface (Levinson et al., 2010).

attribute to OC decreases approximately linearly from 0.43 at $400 \mathrm{~nm}$ to 0.26 at $500 \mathrm{~nm}$ to 0.11 at $600 \mathrm{~nm}$ (Table 1).

Using the model for $f_{\mathrm{OC}}(\lambda)$, we compute (Eq. 6) the fraction of solar radiation that $\mathrm{OC}$ rather than $\mathrm{BC}$ in the wood smoke would absorb in the atmosphere, $F_{\mathrm{OC}}$. We use a model fit for $f_{\mathrm{OC}}(\lambda)$ simply because the wavelength increments of our spectrometer and the solar spectrum data sets differed. As shown in Fig. 3, about half of the sun's energy is in the infrared at $\lambda>700 \mathrm{~nm}$, where $f_{\mathrm{OC}}(\lambda)$ is mostly zero, and about $6 \%$ is in the ultraviolet at $\lambda<400 \mathrm{~nm}$, where $f_{\mathrm{OC}}(\lambda)$ is highest. We find that $14 \%$ of the solar radiation absorbed by the wood smoke particulate matter would be absorbed by OC rather than BC. OC would contribute $49 \%$ of the absorption of ultraviolet solar radiation at wavelengths below $400 \mathrm{~nm}$ (Table 1).

The results of this study depend on the value of the AAE of BC assumed in the apportionment of light attenuation (Fig. 1). To illustrate this sensitivity, we recalculated most results assuming values for $\mathrm{BC} \mathrm{AAE}$ of 1.00 and 1.15 rather than 0.86 (Table 1). The larger the value of BC AAE, the smaller is the contribution of $\mathrm{OC}$ to wood smoke absorption: for BC AAE values of 1.00 and 1.15, OC accounts for $10 \%$ and $7 \%$, respectively, of the solar radiation absorbed by the wood smoke particulate matter.

\section{Significance}

The AAE of OC in wood smoke has potential application for apportionment of solar radiation absorption to different particulate matter species and of atmospheric particulate matter to different sources (e.g., Sandradewi et al., 2008; Favez et al., 2010; Russell et al., 2010; Praveen et al., 2012). The AAE values we report for a large number of wood smoke particulate matter samples (AAE $=1.9, n=115)$ and especially for the light-absorbing $\mathrm{OC}$ fraction $(\mathrm{AAE}=5.0, n=87)$ may be useful in this regard.

The fraction of solar radiation that would be absorbed by OC rather than BC in wood smoke particulate matter (14\%) indicates that $\mathrm{BC}$ is the dominant light-absorbing species in atmospheres burdened with residential wood smoke and OC absorption is secondary but not insignificant. Since the relative amounts of $\mathrm{OC}$ and $\mathrm{BC}$ emitted from fires have been shown to depend on combustion conditions and wood type (e.g., Mazzoleni et al., 2007; McMeeking et al., 2009) and have been reported to vary widely (Piazzalunga et al., 2011), the results of this study apply strictly to the residential wood smoke samples collected in Cambria. The contribution of OC to solar radiation absorption may be more or less in other situations than we find in this study.

A broad comparison can be made with other studies that have characterized particulate matter in regions with open burning (e.g., wildfires in Africa and South America) and residential biofuel combustion (e.g., wood and crop residues used for cooking and heating in Asia). On a global scale, 
these others sources are dominant emitters of carbonaceous particulate matter (Bond et al., 2004). Our results, which show that wood smoke OC and BC absorb a comparable amount of solar radiation at wavelengths below $400 \mathrm{~nm}$, are consistent with those of Hoffer et al. (2006), who found that OC in Amazonian biomass smoke particles contributed up to $50 \%$ of light absorption at $300 \mathrm{~nm}$ and significantly to absorption of broadband solar radiation, and those of Flowers et al. (2010), who found that OC accounted for up to $50 \%$ of the $400 \mathrm{~nm}$ light absorption of particulate matter transported over mainland Asia. These results suggest that $\mathrm{OC}$ absorption may influence tropospheric photochemistry (Li et al., 2011; Vuilleumier et al., 2001). Also, the fraction of light absorbed by $\mathrm{OC}$ rather than $\mathrm{BC}$ in the wood smoke particulate matter in this study is similar to that which we previously reported for samples collected over southern Africa during the dry biomass burning season (Kirchstetter et al., 2004).

The similarities across studies, despite different analytical methods and differences in fuels, combustion processes, and atmospheric processing, indicates that light-absorbing $\mathrm{OC}$ is ubiquitous in atmospheres influenced by biomass and biofuel burning. Since biomass and biofuel combustion generates a major portion of atmospheric carbonaceous particulate matter globally, and since carbonaceous particulate matter affects climate (Ramanathan and Carmichael, 2008), these observations support the notion that light-absorbing OC should be considered when particulate matter effects on the radiative forcing of climate are evaluated (Chakrabarty et al., 2010). It is likely that some but not all climate models in the next assessment of the Intergovernmental Panel on Climate Change will include light-absorbing OC.

Acknowledgements. We thank Stella Tan, Christopher Malejan, and Courtney Ward for collecting samples and Kelley Doyle for analyzing them. We also thank Chelsea Preble for helpful editorial comments. This work was supported by the California Air Resources Board (CARB) under contracts 07-308 and 08-323. The statements and conclusions in this paper are those of the researchers and not necessarily those of CARB. Doyle's participation was supported by the Department of Energy's Summer Undergraduate Research Experience program.

Edietd by: M. K. Dubey

\section{References}

Arnott, W. P., Hamasha, K., Moosmuller, H., Sheridan, P. J., and Ogren, J. A.: Towards aerosol light absorption measurements with a 7-wavelength aethalometer: evaluation with a photoacoustic instrument and a 3-wavelength nephelometer, Aerosol Sci. Technol., 39, 17-29, 2005.

Barnard, J. C., Volkamer, R., and Kassianov, E. I.: Estimation of the mass absorption cross section of the organic carbon component of aerosols in the Mexico City Metropolitan Area, Atmos. Chem. Phys., 8, 6665-6679, doi:10.5194/acp-8-6665-2008, 2008.
Bergstrom, R. W., Pilewskie, P., Russell, P. B., Redemann, J., Bond, T. C., Quinn, P. K., and Sierau, B.: Spectral absorption properties of atmospheric aerosols, Atmos. Chem. Phys., 7, 5937-5943, doi:10.5194/acp-7-5937-2007, 2007.

Bohren, C. F. and Huffman, D. R.: Absorption and Scattering of Light by Small Particles, Wiley-Interscience, New York, USA, 1998.

Bond, T. C.: Spectral dependence of visible light absorption by carbonaceous particles emitted from coal combustion, Geophys. Res. Lett., 28, 4075-4078, 2001.

Bond, T. C., Streets, D. G., Yarber, K. F., Nelson, S. M., Woo, J. H., and Klimont, Z.: A technology-based global inventory of black and organic carbon emissions from combustion, J. Geophys. Res., 109, D14203, doi:10.1029/2003JD003697, 2004.

Chakrabarty, R. K., Moosmüller, H., Chen, L. W. A., Lewis, K., Arnott, W. P., Mazzoleni, C., Dubey, M. K., Wold, C. E., Hao, W. M., and Kreidenweis, S. M.: Brown carbon in tar balls from smoldering biomass combustion, Atmos. Chem. Phys., 10, 63636370, doi:10.5194/acp-10-6363-2010, 2010.

Favez, O., El Haddad, I., Piot, C., Boréave, A., Abidi, E., Marchand, N., Jaffrezo, J. L., Besombes, J. L., Personnaz, M. B., Sciare, J., Wortham, H., George, C., and D'Anna, B.: Inter-comparison of source apportionment models for the estimation of wood burning aerosols during wintertime in an Alpine city (Grenoble, France), Atmos. Chem. Phys., 10, 5295-5314, doi:10.5194/acp-10-52952010, 2010.

Flowers, B. A., Dubey, M. K., Mazzoleni, C., Stone, E. A., Schauer, J. J., Kim, S. W., and Yoon, S. C.: Optical-chemicalmicrophysical relationships and closure studies for mixed carbonaceous aerosols observed at Jeju Island, 3-laser photoacoustic spectrometer, particle sizing, and filter analysis, Atmos. Chem. Phys., 10, 10387-10398, doi:10.5194/acp-10-10387-2010, 2010.

Gyawali, M., Arnott, W. P., Lewis, K., and Moosmüller, H.: In situ aerosol optics in Reno, NV, USA during and after the summer 2008 California wildfires and the influence of absorbing and non-absorbing organic coatings on spectral light absorption, Atmos. Chem. Phys., 9, 8007-8015, doi:10.5194/acp-9-8007-2009, 2009.

Hoffer, A., Gelencser, A., Guyon, P., Kiss, G., Schmid, O., Frank, G. P., Artaxo, P., and Andreae, M. O.: Optical properties of humic-like substances (HULIS) in biomass-burning aerosols, Atmos. Chem. Phys., 6, 3563-3570, doi:10.5194/acp-6-3563-2009, 2006.

IPCC Climate Change 2007: Working Group I: The Physical Science Basis, available at: http://www.ipcc.ch/publications_and_ data/ar4/wg1/en/contents.html, 2007.

Kirchstetter, T. W.: Evaluating past and improving present and future measurements of black carbon particles in the atmosphere. California Energy Commission, PIER Energy-Related Environmental Research. Final report CEC500-2007-042, http://www.energy.ca.gov/2007publications/ CEC-500-2007-042/CEC-500-2007-042.PDF, 2007.

Kirchstetter, T. W., Novakov, T., and Hobbs, P. V.: Evidence that spectral light absorption by aerosols emitted from biomass burning and motor vehicles is different due to organic carbon, J. Geophys. Res., 109, D21208, doi:10.1029/2004JD004999, 2004.

Levinson, R., Akbari, H., and Berdahl, P.: Measuring solar reflectance - Part I: defining a metric that accurately predicts solar heat gain, Solar Energy, 84, 1717-1744, 2010. 
Li, G., Bei, N., Tie, X., and Molina, L. T.: Aerosol effects on the photochemistry in Mexico City during MCMA2006/MILAGRO campaign, Atmos. Chem. Phys., 11, 51695182, doi:10.5194/acp-11-5169-2011, 2011.

Mazzoleni, L. R., Zielinska, B., and Moosmüller, H.: Emissions of levoglucosan, methoxy phenols, and organic acids from prescribed burns, laboratory combustion of wildland fuels, and residential wood combustion, Environ. Sci. Technol., 41, 21152122, 2007.

McMeeking, G. R., Kreidenweis, S. M., Baker, S., Carrico, C. M., Chow, J. C., Collett, J. L., Hao, W. M., Holden, A. S., Kirchstetter, T. W., Malm, W. C., Moosmüller, H., Sullivan, A. P., and Wold, C. E.: Emissions of trace gases and aerosols during the open combustion of biomass in the laboratory, J. Geophys. Res., 114, D19210, doi:10.1029/2009JD011836, 2009.

Moosmüller, H., Chakrabarty, R. K., Ehlers, K. M., and Arnott, W. P.: Absorption Ångström coefficient, brown carbon, and aerosols: basic concepts, bulk matter, and spherical particles, Atmos. Chem. Phys., 11, 1217-1225, doi:10.5194/acp-11-12172011, 2011.

Piazzalunga, A., Belis, C., Bernardoni, V., Cazzuli, O., Fermo, P., Valli, G., and Vecchi, R.: Estimates of wood burning contribution to PM by the macro-tracer method using tailored emission factors, Atmos. Environ., 45, 6642-6649, 2011.

Praveen, P. S., Ahmed, T., Kar, A., Rehman, I. H., and Ramanathan, V.: Link between local scale BC emissions and large scale atmospheric solar absorption, Atmos. Chem. Phys., 12, 1173-1187, doi:10.5194/acp-12-1173-2012, 2012.

Ramanathan, V. and Carmichael, G.: Global and regional climate changes due to black carbon, Nature Geosci., 1, 221-227, 2008.

Rizzo, L. V., Correia, A. L., Artaxo, P., Procopio, A. S., and Andreae, M. O.: Spectral dependence of aerosol light absorption over the Amazon Basin. Atmos. Chem. Phys., 11, 8899-8912, doi:10.5194/acp-11-8899-2011, 2011.
Russell, P. B., Bergstrom, R. W., Shinozuka, Y., Clarke, A. D., DeCarlo, P. F., Jimenez, J. L., Livingston, J. M., Redemann, J., Dubovik, O., and Strawa, A.: Absorption Angstrom Exponent in AERONET and related data as an indicator of aerosol composition, Atmos. Chem. Phys., 10, 1155-1169, doi:10.5194/acp-101155-2010, 2010.

Sandradewi, J., Prevot, A. S. H., Szidat, S., Perron, N., Alfarra, M. R., Lanz, V. A., Weingartner, E., and Baltensperger, U.: Using aerosol light absorption measurements for the quantitative determination of wood burning and traffic emission contributions to particulate matter, Environ. Sci. Technol., 42, 3316-3323, doi:10.1021/es702253m, 2008.

Schmid, O., Artaxo, P., Arnott, W. P., Chand, D., Gatti, L. V., Frank, G. P., Hoffer, A., Schnaiter, M., and Andreae, M. O.: Spectral light absorption by ambient aerosols influenced by biomass burning in the Amazon Basin. I: Comparison and field calibration of absorption measurement techniques, Atmos. Chem. Phys., 6, 3443-3462, doi:10.5194/acp-6-3443-2006, 2006.

Sun, H., Biedermann, L., and Bond, T. C.: Color of brown carbon: A model for ultraviolet and visible light absorption by organic carbon aerosol, Geophys. Res. Lett., 34, L17813, doi:10.1029/2007GL029797, 2007.

Thatcher, T., Tan, S., Malejan, C., Ward, C., and Kirchstetter, T.: Assessing Near-Field Exposures from Distributed Residential Wood Smoke Combustion Sources, Final report to California Air Resources Board, 2011.

Vuilleumier, L., Bamer, J. T., Harley, R. A., and Brown, N. J.: Evaluation of nitrogen dioxide photolysis rates in an urban area using data from the 1997 Southern California Ozone Study, Atmos. Environ, 35, 6525-6537, doi:10.1016/S1352-2310(01)00379-X, 2001.

Weingartner, E., Saathoff, H., Schnaiter, M., Streit, N., Bitnar, B., and Baltensperger, U.: Absorption of light by soot particles: determination of the absorption coefficient by means of aethalometers, J. Aerosol Sci., 34, 1445-1463, 2003. 